Research Article

\title{
Analysis of the Effectiveness and Study on Long-Term Mechanism of Sports World Campus App in Monitoring Extracurricular Physical Exercise of College Students
}

\author{
Liang Meng $\mathbb{D}^{1}$ and Jianmin $\mathrm{Li}^{2}$ \\ ${ }^{1}$ Sports Department, Suzhou University of Science and Technology, Suzhou 215000, Jiangsu, China \\ ${ }^{2}$ College of Tai Chi Culture, Handan University, Handan 056005, Hebei, China \\ Correspondence should be addressed to Liang Meng; mengliang@usts.edu.cn
}

Received 5 August 2021; Revised 13 September 2021; Accepted 22 September 2021; Published 5 October 2021

Academic Editor: Sang-Bing Tsai

Copyright ( 92021 Liang Meng and Jianmin Li. This is an open access article distributed under the Creative Commons Attribution License, which permits unrestricted use, distribution, and reproduction in any medium, provided the original work is properly cited.

\begin{abstract}
The data of extracurricular physical exercise of college students before, at the time of, and after being monitored were compared and analyzed by the Sports World Campus app (a running app), and it was concluded as follows: (1) compared with the data before being monitored, the average number of running times per week and the proportion of physical education population increased significantly during and after being monitored; (2) compared with the data the time of being monitored, the average number of running times per week and the proportion of physical education population decreased significantly after being monitored; and (3) per academic year, the average number of running times per week and the time of running increased year by year in the three years of being monitored. To derive a long-term mechanism, it is necessary to (1) raise the attention of school authorities, strengthen the supervision in management, and formulate a reasonable reward and punishment system; (2) optimize the quality of running apps to improve students' sense of running experience; (3) set a reasonable amount of tasks per semester to guide students to conduct extracurricular physical exercise scientifically; and (4) promote students' overall development, establish a culture of extracurricular physical activities, and cultivate students' lifelong sports awareness.
\end{abstract}

\section{Introduction}

In recent years, China has attached great importance to the physical health of students. In 2012, the National Conference clearly put forward the strategic position of school sports as "strengthening physical education classes and extracurricular exercises to promote the physical and mental health and fitness of teenagers" [1]. In 2018, President Xi put forward the "four-in-one goal" of "establishing the education concept of prioritizing health, comprehensively deepening school physical education work, and helping students to enjoy physical exercise, strengthen physique, improve their personality and temper their will" at the National Education Conference [2]. It embodies the core idea of school physical education. It also carries out the requirements of "Basic standards for physical education in higher education" and
"Guidance on the in-depth development of mass extracurricular physical activities of college students 'going off the Internet, out of the dormitory and to the playground'," effectively promoting the development of students' healthy lifestyles, improving their physical health, cultivating their lifelong sports consciousness, and further promoting the process of "inside and outside class integration".

Because of China attaching importance to students' physical health and with the rapid development of Internet technology, the integration of both sports and the Internet becomes increasingly closer [3]. Since the twenty-first century, smartphones have been popularized in China, and various Internet companies have launched various mobilebased applications to meet the needs of people. More powerful functions than the small plug-ins such as social software are available, which can meet the fitness guidance 
and sports data recording and analysis needed by college students for extracurricular sports activities, and is highly welcomed by college students. These applications can be used by teachers to monitor students' after-school exercise, and students can use them to know the details of their running behaviors. Thus, it can be seen that the Sports World Campus app (hereinafter referred to as App) is a product of sports technology, having a positive effect on the promotion of physical exercise.

In order to effectively promote the development of a healthy lifestyle among students, improve their levels of physical health, and develop a lifelong awareness of physical education, Suzhou University of Science and Technology has been using the Sports World Campus app for three years. To monitor the effect of extracurricular physical exercise and take it as a part of evaluating students' final PE grades, this paper analyzes the data before, during, and after the monitoring period, which is meant to analyze the effect of exercise, to study and monitor the long-term mechanism.

\section{Object of the Study}

The object of study is "analysis of the effectiveness and study on long-term mechanism of Sports World Campus app in monitoring extracurricular physical exercise of college students,", and the object of the survey is "freshmen, sophomores, juniors, and seniors of Suzhou University of Science and Technology and their use of App."

\section{Purpose of the Study}

Through the running app, Sports World Campus, the data before, at the time of, and after monitoring the extracurricular physical exercise of college students were compared and analyzed to investigate whether the running app can effectively promote the development of students' awareness of physical exercise. And through data comparison, we analyze the reasons for such results and study the long-term mechanism to promote students' physical exercise.

\section{Methods of the Study}

The data before and after monitoring were obtained from the questionnaire survey, and the data during monitoring were provided by the App background of the Sports World Campus. The data at the time of the monitoring was legal because students had signed up to a "privacy policy" at the time of their registration, allowing their data to be used in scientific research.

4.1. Questionnaire Method. According to the object of study and its content, the basic method of questionnaire design was followed, and the App is used to investigate and study the number of weekly running frequency, the time of each run, and the average frequency of runs per week of students of Suzhou University of Science and Technology before and after being monitored by the App. The questionnaire was tested for reliability by experts and then distributed. The questionnaires were distributed for students to fill in independently and then collected on the spot. One thousand questionnaires were distributed in all grades of the undergraduate program and each college and major, and 1000 questionnaires were collected, with a $100 \%$ recovery rate. Around 941 questionnaires are valid, with a percentage of $94 \%$.

4.2. Mathematical and Statistical Methods. Firstly, software Excel 2000 was used to organize and filter the background data and survey data of the Sports World Campus app, and then SPSS 16.0 was used to statistically process the data.

\section{Review of the Literature}

\subsection{Definition of Related Concepts}

5.1.1. Extracurricular Physical Exercise. Extracurricular physical exercise is an important extension and supplement of school physical education and also one of the important ways to achieve the goal of school physical education. Professor Zhou's main forms of extracurricular physical exercise include school form (interclass exercise, morning exercise, after-school competition, after-school training, and after-school exercise), class form (class physical activity), and individual form (students' own physical exercise) [4]. According to the needs of this study, extracurricular physical exercise is defined as physical activity for the purpose of improving students' physical quality by taking the form of physical exercise in extracurricular time.

5.1.2. A Long-Term Mechanism. The word "mechanism" originally refers to the structure and production and processing principle of the machine [5]. Later, in sociology, it is used to illustrate the operation process, development, and connection of social organizations. The so-called "long-term mechanism" refers to the institutional system established to promote the effective operation of the organization's operation process. The long-acting mechanism shifts with the changes in all aspects of its interior and makes effective adjustments according to the changes in all aspects of the interior. In terms of youth ice and snow sports training, institutions should constantly understand the needs of all parties and integrate all resources so as to form an organic whole and establish a scientific operation system.

5.2. The Research Status. At present, not many research studies about the effect and long-term mechanism of sports applications are available to monitor the extracurricular physical exercise of college students. In the article by Feng [6], documentary method, questionnaire survey method, mathematical and statistical method, logical method, and other methods were used to study the use of the Sports World Campus app by college students and physical education teachers in Henan Province, and it analyzed the influence of Sports World Campus on students' running behaviors, and it was concluded that the proportion of the participants of health running among college students in Henan Province increased after using the Sports World 
Campus app, and the frequency of running among college students in Henan Province increased greatly after using the Sports World Campus app than before using it [6]. Feng only analyzed the data from the perspective of running frequency but did not study the long-term effect of using the software, which remains blank in this field of research. This study not only analyzes and compares the data of students before, during, and after using the exercise app but also makes a study on how it can make students' physical exercise have long-term effects.

\section{Study Results and Analysis}

6.1. Exercise Requirements for Using the Sports World Campus App of SUST. Suzhou University of Science and Technology began promoting and using the Sports World Campus app in September 2018 for freshmen, sophomores, juniors, and seniors attending public physical education courses. The monitoring time period was from the second week to Friday of the $16^{\text {th }}$ week of the semester. The data of the freshmen and sophomores were obtained from the background data monitored. Table 1 shows the requirements of extracurricular physical exercise in this questionnaire survey.

6.2. Comparison of Students' Extracurricular Physical Exercise before, during, and after Being Monitored by the Sports World Campus App. Persistence in physical exercise refers to the tendency of people to regularly engage in physical activities with a certain intensity in order to achieve a certain exercise purpose and to show a continuous or lasting behavior in the process, which can be estimated by the exercise and its frequency. Improving persistence in physical exercise is important for promoting students' physical health [4].

From Tables 2-4, it can be seen that there are changes in the number of students' weekly running frequency before, at the time of, and after being monitored by the Sports World Campus app.

6.3. Comparison of Students' Extracurricular Physical Exercise before and at the Time of Being Monitored by the Sports World Campus App. From Table 5, the chi-square test showed that $X 2=14.242, P<0.05$. There were differences between the results before and at the time of being monitored. Compared to students' extracurricular physical exercise before being monitored, the number of students running 0 and 1-2 times per week at the time of being monitored is decreasing, and the number of students running 3-5 times and 5 times or more is increasing.

6.4. Comparison of Students' Extracurricular Physical Exercise before, at the Time of, and after Being Monitored by the Sports World Campus App. From Table 6, the chi-square test showed that $X 2=12.968, P<0.05$. There were differences between the results at the time of and after monitoring. More than students' extracurricular physical exercise at the time of being monitored, the number of students running 0 and 1-2 times per week is improving after being monitored, and the number of students running 3-5 times and 5 times or more is decreasing.

Figure 1 shows that compared with the frequency of running at the time of being monitored, the frequency of running after being monitored showed a decreasing trend. Among them, those who ran once a week or more account for $82.5 \%$ of the total number of runners at the time of being monitored; those who ran 3 times a week or more only account for $36.0 \%$ of the total number of runners at the time of being monitored, and those who ran 5 times a week or more only account for $11.0 \%$ of the number of runners at the time of being monitored.

From Tables 4-7 and Figure 1, it is known that the promotion of running exercise via the Sports World Campus app has a great promoting effect on college students' participation in exercise and can effectively promote students' persistence in physical exercise.

6.5. Comparison of Students' Extracurricular Physical Exercise before and after Being Monitored by the Sports World Campus App. From Table 7, the chi-square test showed that $X 2=14.260, P<0.05$. There were differences between the results before and after being monitored. Compared to students' extracurricular physical exercise before being monitored, the number of students running $0,3-5$, and $>5$ times per week is decreasing, and the number of 1-2 times per week is improving after being monitored.

6.6. Situation of Extracurricular Physical Exercise of Freshmen and Sophomores Each Academic Year Being Monitored via the Sports World Campus App. Figure 2 shows that the number of students who ran $0,1-2,3-5$, and 5 times or more per week in the first academic year were 240, 3,082, 6,205, and 2,155 , respectively; the number of students who ran $0,1-2$, $3-5$, and 5 times or more per week in the second academic year were $35,522,8,560$, and 2,543 , respectively; and the number of students who ran $0,1-2,3-5$, and 5 times or more per week in the third academic year were $62,123,9,924$, and 1492 , respectively. The number of students who did not run per academic year decreased year by year, and the number of students who ran 3-5 times a week increased year by year.

Figure 3 shows that the average number of running times per week for students in the first, second, and third academic years were $2.9,3.0$, and 3.1, respectively, and the average number of minutes per run for students in the first, second, and third academic years were 30.1, 31.2, and 33.3, respectively. The number of running times per week and the time per run of students were increasing year by year.

Figure 4 shows that the number of active people per week is relatively high in weeks $2-6$, the number of active people per week is the lowest in weeks 7-11, and the number of active people per week is the highest in weeks 12-16. This shows the characteristic of high at both ends and low in the middle, which indicates that students did not plan their running time and frequency reasonably, and thus led to the phenomenon of "piling up" running in the same period. In the first 5 weeks, the activeness may be due to the teachers' emphasis on running in class and the freshness from 
Table 1: Exercise requirements of using the Sports World Campus app at SUST $(N=941)$.

\begin{tabular}{|c|c|c|c|c|c|c|}
\hline $\begin{array}{l}\text { Time of } \\
\text { morning } \\
\text { run }\end{array}$ & $\begin{array}{l}\text { Time of } \\
\text { non- } \\
\text { morning } \\
\text { run }\end{array}$ & $\begin{array}{l}\text { Frequency of } \\
\text { morning run }\end{array}$ & $\begin{array}{l}\text { Frequency of } \\
\text { non-morning } \\
\text { runs }\end{array}$ & $\begin{array}{l}\text { Requirements for } \\
\text { kilometers }\end{array}$ & $\begin{array}{l}\text { Requirements } \\
\text { for speed }\end{array}$ & Award and punishment \\
\hline $5: 30-7: 30$ & $7: 31-22: 00$ & 15 times & 30 times & $\begin{array}{l}\text { No less than } 2,000 \text { meters } \\
\text { for male students and no } \\
\text { less than } 1,500 \text { meters for } \\
\text { female students }\end{array}$ & $\begin{array}{c}2 \mathrm{~min} \\
11 \mathrm{sec}-10 \mathrm{~min}\end{array}$ & $\begin{array}{l}\text { All the times completed, and } \\
\text { the final total score of physical } \\
\text { education class plus } 5 \text { points, of } \\
\text { which } 0.5 \text { points will be } \\
\text { deducted for each time missed }\end{array}$ \\
\hline
\end{tabular}

TABLE 2: Weekly running frequency statistics before being monitored by the Sports World Campus app $(N=941)$.

\begin{tabular}{lcccccccc}
\hline & \multicolumn{4}{c}{ Before being monitored } \\
Number of people/proportion & \multicolumn{4}{c}{ Exercise time } & \multicolumn{4}{c}{ Exercise frequency } \\
& $\leq 30 \mathrm{~min}$ & $31-40 \mathrm{~min}$ & $41-60 \mathrm{~min}$ & $>60 \mathrm{~min}$ & 0 times & $1-2$ times & $3-5$ times & $>5$ times \\
\hline Number of people & 632 & 180 & 82 & 47 & 321 & 225 & 294 \\
Proportion (\%) & 67 & 19 & 9 & 5 & 34 & 24 & 31 & 101 \\
\hline
\end{tabular}

TABLE 3: Weekly running frequency statistics at the time of being monitored by the Sports World Campus app $(N=941)$.

\begin{tabular}{lcccccccc}
\hline & \multicolumn{4}{c}{ At the time of being monitored } \\
Number of people/proportion & \multicolumn{4}{c}{ Exercise time } & \multicolumn{4}{c}{ Exercise frequency } \\
& $\leq 30 \mathrm{~min}$ & $31-40 \mathrm{~min}$ & $41-60 \mathrm{~min}$ & $>60 \mathrm{~min}$ & 0 times & $1-2$ times & $3-5$ times & $>5$ times \\
\hline Number of people & 120 & 724 & 62 & 35 & 126 & 132 & 390 & 293 \\
Proportion (\%) & 13 & 77 & 7 & 3 & 13 & 14 & 41 & 32 \\
\hline
\end{tabular}

TABLE 4: Weekly running frequency statistics after being monitored by the Sports World Campus app $(N=941)$.

\begin{tabular}{lcccccccc}
\hline & \multicolumn{4}{c}{ After being monitored } \\
Number of people/proportion & \multicolumn{4}{c}{ Exercise time } & \multicolumn{4}{c}{ Exercise frequency } \\
& $\leq 30 \mathrm{~min}$ & $31-40 \mathrm{~min}$ & $41-60 \mathrm{~min}$ & $>60$ min & 0 times & $1-2$ times & $3-5$ times & $>5$ times \\
\hline Number of people & 694 & 180 & 52 & 15 & 298 & 338 & 215 \\
Proportion (\%) & 74 & 19 & 5 & 2 & 32 & 36 & 23 & 9 \\
\hline
\end{tabular}

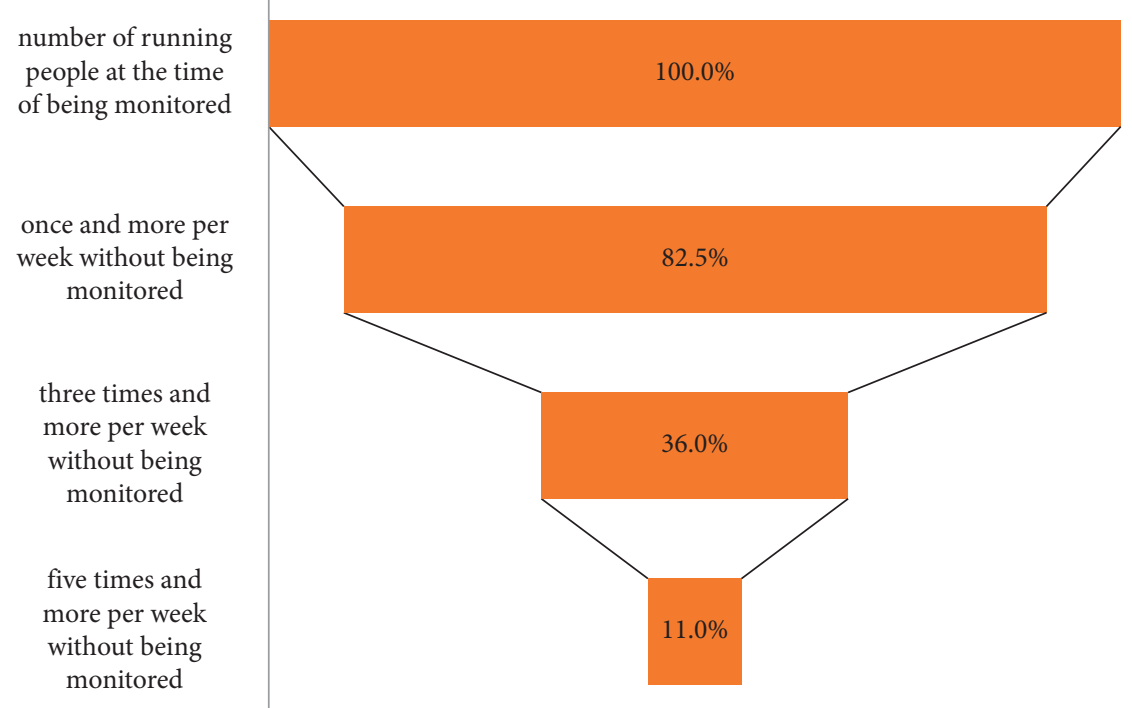

Figure 1: Conversion rate of the number of students in terms of running frequency per week before and after being monitored. 
TABle 5: Analysis of the difference in the number of people in terms of running frequency per week before and at the time of being monitored.

\begin{tabular}{|c|c|c|c|c|}
\hline Frequency/number of people & 0 times & $1-2$ times & $3-5$ times & $>5$ times \\
\hline Before being monitored & 321 & 225 & 294 & 101 \\
\hline At the time of being monitored & 126 & 132 & 390 & 293 \\
\hline Inspection & \multicolumn{4}{|c|}{$X^{2}=14.242 P<0.05$} \\
\hline
\end{tabular}

TABLE 6: Analysis of the differences in the number of people in terms of running frequency per week before and at the time of being monitored.

\begin{tabular}{|c|c|c|c|c|}
\hline Frequency/number of people & 0 times & $1-2$ times & $3-5$ times & $>5$ times \\
\hline At the time of being monitored & 126 & 132 & 390 & 293 \\
\hline After being monitored & 298 & 338 & 215 & 90 \\
\hline Inspection & \multicolumn{4}{|c|}{$X^{2}=12.968 P<0.05$} \\
\hline
\end{tabular}

TABLE 7: Analysis of the differences in the number of people in terms of running frequency per week before and after being monitored $(=941)$.

\begin{tabular}{lcccc}
\hline Frequency/number of people & 0 times & $1-2$ times & $3-5$ times & More than 5 times \\
\hline Before being monitored & 321 & 225 & 294 & 101 \\
After being monitored & 298 & 338 & 215 & 90 \\
Inspection & & & $X^{2}=14.260 P<0.05$ & \\
\hline
\end{tabular}

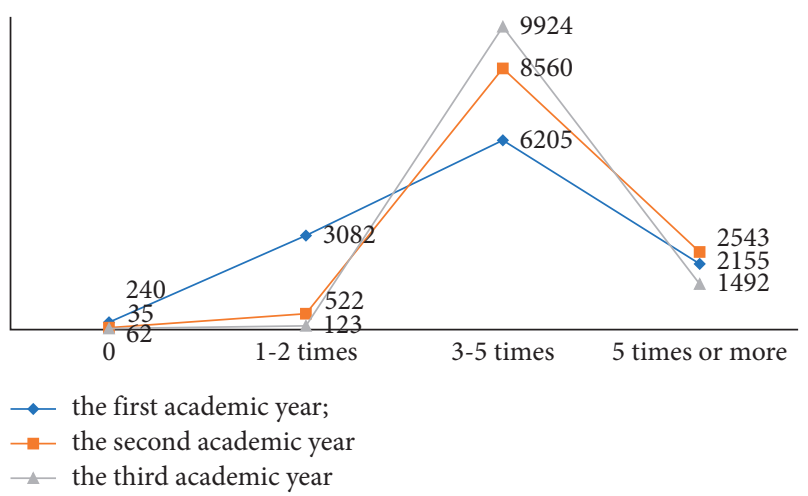

Figure 2: Comparison of data on the number of freshmen and sophomores in terms of weekly running frequency per academic year at the time of being monitored.

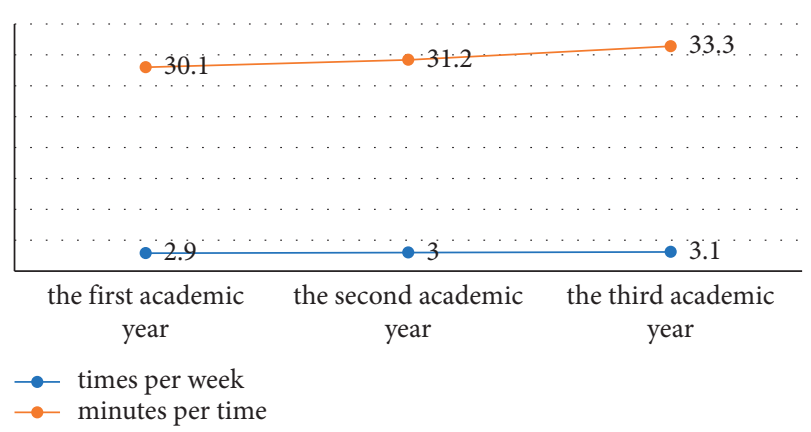

FIGURE 3: Number of runs per week and time per run of freshmen and sophomores per academic year at the time of being monitored.

freshmen, but in the middle 5 weeks, the frequency of daily activeness decreased due to the teachers' insufficient supervision and students' own reasons. In the last 5 weeks,

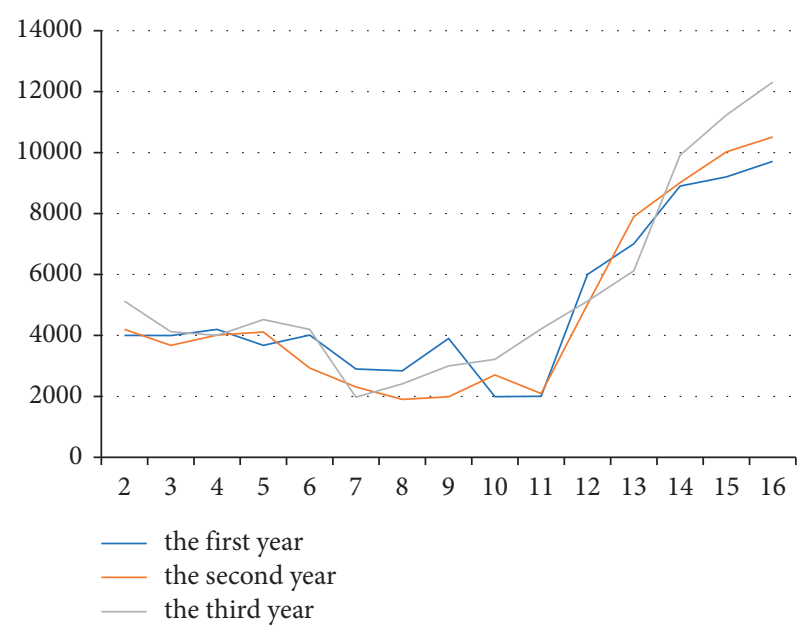

Figure 4: Average numbers of active students per week per academic year at the time of being monitored.

approaching the end of the semester, students were eager to finish their tasks, and the daily average number of active people increased dramatically.

Based on Figure 5, the students' daily running time periods show the same curve in each academic year.

The schedules 6:00-7:00, 15:00-17:00, and 19:00-21:00 were the three peak running periods. The peak time of students' clocking in for running was from 6:00 to 7:00, because 5:30-7:00 was the scheduled time to clock in for morning exercises and they had to finish 15 times per semester. The non-peak time was from 8:00 to 14:00, which is related to the students having courses at this time per week. Two peak periods of students' running are ones from 15:00 to $17: 00$ and from 19:00 to $21: 00$, which are closely related to the students' courses and rest. 


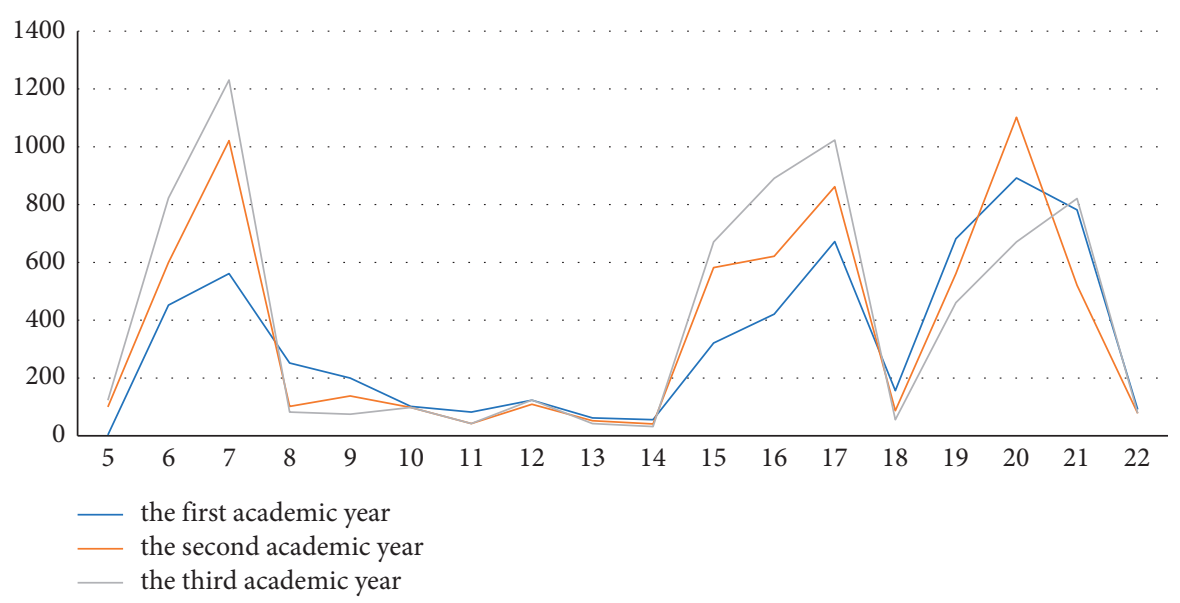

Figure 5: Number of students active at each time of day per academic year at the time of being monitored.

According to a study, the best time for muscle excitement, strength, and endurance of the human body is between 7:00-11:00 and 15:00-18:00 daily, and the physical exercise and training during this time will have better results. Obviously, using the Sports World Campus app to monitor extracurricular physical exercise not only promotes students' habit of running after school but also enables them to choose the best time for running.

\subsection{Effects after Using Running Apps}

(1) Compared with the time before being monitored, the frequency of students running per week, the time spent per run, and the percentage of sports population at the time of being monitored were significantly higher. Compared with the time before being monitored, the frequency of students running per week, the time spent per run, and the percentage of sports population were significantly higher after being monitored. Compared to the time of being monitored, the frequency of students running per week, the time spent per run, and the percentage of sports population decreased significantly after being monitored, but $90 \%$ of students switched to sports population.

(2) In the two years of being monitored, the average number of weekly runs and the time of each run per academic year showed an increase year by year, and the number of students who did not run per week decreased year by year.

(3) To a certain extent, being monitored urged students to develop their habits of running outside of class and also prompted them to choose the best time for running.

(4) The atmosphere of school sports has improved, and students can be seen everywhere on campus doing extracurricular sports activities.

\subsection{Shortcomings after Using Running Apps}

(1) The students' weekly running frequency is uneven, and the running requirements are not well set for each semester

(2) The university does not pay enough attention to comprehensive management, and the reward and punishment system is not reasonable enough

(3) The software itself is not perfect, and students have a poor experience in using it

(4) At the time of being monitored, the average number of running times per week, time per run, and the number of running frequency per week of students increased significantly, and after being monitored, the data decreased significantly, and students' exercise habits were not fully developed

\section{Study on the Long-Term Mechanism of Extracurricular Physical Exercise}

In order to maintain the good effects achieved by the use of the Sports World Campus app in the past two years in SUST, we have killed off the shortcomings such as uneven frequency of weekly running, unreasonable reward and punishment system of the school, inadequate software, and the good effects not being transferred to senior students. The following long-term mechanism of extracurricular physical exercise is summarized.

7.1. Raising the Attention of School Authorities, Strengthening the Supervision in Management, and Formulating a Reasonable Reward and Punishment System. School authorities should pay high attention to the situation of extracurricular physical exercise for students, set up a special group for it, and establish a monitoring system at different levels. This group can be headed by the principal in charge of sports, and the sports department, colleges, school committee, and 
academic affairs department can coordinate with each other to understand the requirements of students' extracurricular exercise solve its pain points and help students raise interest in extracurricular exercise.

At present, the Department of Physical Education only uses the results of the Sports World Campus app as a part of the physical education class, and although the data of students' use of the Sports World Campus app have improved every year, some students fail to complete tasks raised by it every year, and it is common for students to cheat by running without obeying rules. Colleges and universities must formulate relevant rules and regulations to guarantee the normal development of extracurricular physical exercise for students, and the system must have a certain degree of restraint, guidance, motivation, standardization, and rationality. For example, the use of the Sports World Campus app should be included in the evaluation of merits and awards at all levels, and cheating behaviors should no longer be involved in the evaluation of merits and awards, and serious cases should be dealt with according to the discipline of cheating in exams. A reasonable reward and punishment system should also be developed to praise the advanced and establish the typical to promote the in-depth implementation of extracurricular physical exercise. Praising the advanced and setting up the typical can be the relevant organizers and teachers in charge or the students who perform well to enhance their respective sense of achievement. Therefore, the development of a reasonable reward and punishment system is a catalyst for the implementation of extracurricular physical exercise.

\subsection{Optimizing Product Quality and Improving Running} Experience. The main problems of the Sports World Campus app include inaccurate GPS positioning, loss of running data records [7], unstable server, and low efficiency in problem-solving, which often reduce students' running experience, make them resist, and even cause them to cheat. If these problems cannot be solved, students' motivation to run will be greatly weakened, which is extremely unfavorable to the development of extracurricular physical exercise. Therefore, the Sports World Campus app should consider optimizing the quality of the product, making the software run smoothly, and improving the running experience.

7.3. Setting a Reasonable Amount of Tasks per Semester to Guide Students to Conduct Extracurricular Physical Exercise Scientifically. The tasks of 45 times of SUST each semester are at least 15 times for morning exercises and 30 times for non-morning exercises. From the above icons, we can see that the frequency of students' weekly extracurricular physical exercise is unstable, with the characteristic of high at both ends and low in the middle. The frequency of students' weekly running is not scientific because the rules are not reasonable. The number of active students and the frequency of running on the last five days of each semester increased significantly, while the number of active students on the middle five days was the lowest. It is possible to set the task of running 3 times a week, and the corresponding score can be obtained only after completing it three times. This will avoid the pile-up of running at the end of the semester and better prevent students from cheating.

Meanwhile, from the perspective of the time of students' daily running, 6:00-7:00, 15:00-17:00, and 19:00-21:00 are the three peak periods for running. And 8:00-12:00 and 14: 00-17:00 are better running times every day. If you want to guide students to do extracurricular physical exercise in this time, you can design double points to encourage students to punch cards in this time period to promote students' physical and mental health more effectively.

\subsection{Promoting Students' All-Round Development, Establish-} ing a Culture of Extracurricular Sports Activities, and Cultivating Students' Lifelong Sports Awareness. According to Professor Liu, "Emphasis is placed on promoting the healthy development of students through the teaching of physical education and health knowledge, skills and methods" [8]. In the new era, the new curriculum reform requires new ideas and initiatives. Wang believes that physical education competencies should include "the ability to exercise, self-adjust, and self-evaluate, and the ability to deal with interpersonal relationships and social interactions" [9]. Physical education competency is a kind of competency structure that can be called "physical education practice competency," which is a comprehensive competency that students should have when they engage in lifelong physical exercise and sports recreation [10]. Extracurricular physical exercise is only a way for students to exercise themselves, and comprehensive development requires students to have a stronger sense of physical activity, self-regulation, and self-cognitive ability.

The single form of monitoring may be an important reason why students eventually have difficulty in developing a sense of exercise, and there are various measures that can be taken to compensate for the single form of monitoring. For example, (1) reward for varsity training: students who participate in sports varsity team and complete the required number of training will be given the policy of adding the number of running times; (2) reward for sports club activities: students who participate in various sports club activities can add one running time for every activity they participate in for more than 60 minutes if their attendance rate is above $60 \%$, and those whose attendance rate is below $60 \%$ will not increase the number of running times; and (3) other sports activities rewards: students participate in other sports activities such as school athletic performance, campus sports activities, and so on to increase the number of policies, the specific number of increases according to the actual situation to determine a reasonable reward.

Through the above initiatives, we can promote the overall development of students' physical activities, make running and other forms of extracurricular physical exercise fully developed in the school at the same time, increase the population base of various sports in the school, and send talents to school sports teams. Ultimately, a culture of extracurricular physical activity is established to promote the development of exercise habits and a sense of lifelong physical awareness. 


\section{Conclusion}

(1) Monitoring extracurricular physical activities in colleges and universities via running apps, which affects students' exercise habits at a certain time and to a certain extent, increases the number of students' extracurricular exercise and improves the atmosphere of school sports. However, if the school does not take extracurricular physical exercise as a part of students' physical education class performance, as a condition of merit evaluation and award at all levels, and linked to students' personal interests, students' extracurricular physical exercise is not active. Monitoring and supervision are only means, not the purpose. The original purpose of running apps to monitor extracurricular physical activities in colleges and universities is to promote students' physical and mental health, cultivate good exercise habits, and improve lifelong sports awareness.

(2) Monitoring students' extracurricular physical exercise via running apps is only one way to comprehensively improve students' physical health, which requires the following:

(i) Improving students' physical exercise system, incorporating students' extracurricular physical activities into teaching plans and rest time, innovating extracurricular exercise mode, and effectively ensuring students' daily one-hour campus physical activities [11]

(ii) Strengthening the study on extracurricular exercise system and enhancing the study on extracurricular exercise mode, sports talents training and training theory from the perspectives of sports competition science, sports training science, and material selection science to ensure the scientific and standardized nature of extracurricular exercise in school sports

(iii) To form a situation where colleges, grades, and classes work together to promote students' physical exercise and improve their physical health and to build a governance system where colleges, grades, and classes work together and govern extracurricular physical exercise in schools, creating a good atmosphere for development

(3) In the decisive stage of building a moderately prosperous society and the historical intersection of our country's Two Centenary Goals, it is an important task for our school sports people to modernize education, build a strong country in education and sports, and comprehensively promote the balanced development of education.

\section{Data Availability}

Data sharing is not applicable to this article as no datasets were generated or analyzed during the current study.

\section{Disclosure}

Liang Meng and Jianmin Li are co-first authors.

\section{Conflicts of Interest}

The authors declare that they have no conflicts of interest.

\section{Authors' Contributions}

Liang Meng and Jianmin Li contributed equally to this work.

\section{References}

[1] H. Xu and X. Li, "Review of school sports development in the 40 years of reform and opening up and new orientation and perspective of reform and development in the new era," Journal of Beijing Sport University, vol. 42, no. 5, pp. 34-43, 2019.

[2] "Study on Xi Jinping's thought of building a strong sports country in the new era and its value," Journal of Nanjing Sports Institute, vol. 1, no. 3, pp. 1-11, 2018.

[3] H. Hamidi and M. Jahanshahifard, "The role of the internet of things in the improvement and expansion of business," Journal of Organizational and End User Computing, vol. 30, no. 3, pp. 24-44, 2018.

[4] D. Zhou, School Physical Education, People's Sports Publishing House, Beijing, China, 2004.

[5] p. 12, 2003 A dictionary of new words and expressions.

[6] P. Feng, Research on the Impact of the Use of Sports World Campus App on College Students' Campus Health Running Behavior in Henan Province, Henan University, Kaifeng, China, 2018.

[7] M. Zhou, Y. Wang, Y. Liu, and Z. Tian, "An informationtheoretic view of WLAN localization error bound in GPSdenied environment," IEEE Transactions on Vehicular Technology, vol. 68, no. 4, pp. 4089-4093, 2019.

[8] J. Liu and D. Ma, "Review and prospect of the development of school sports in China in the 40 years of reform and opening up," Research in Physical Education, vol. 1, no. 5, pp. 1-11, 2018.

[9] Z. Wang, Reform of Curriculum and Teaching Materials and Physical Education Syllabus Experiments-Nine-Year Compulsory Education Full-Time Elementary School Physical Education Syllabus (Trial) Study Guide, People's Education Press, Beijing, China, 1994.

[10] Z. M. Mao, Exploration of the Scientization of Physical Education Teaching, Higher Education Press, Beijing, China, 1999.

[11] L. Yan and J. Zhang, "Research on ways to cultivate physical exercise atmosphere on campus of colleges and universities," Journal of Physical Culture, vol. 36, no. 3, pp. 113-117, 2018. 